\title{
DEH KIDZ IN JAMAICA: AN EVALUATION REPORT ABOUT A COMMUNITY ORGANIZATION SERVING CHILDREN AND ADOLESCENTS
}

\author{
Leslie Yaffa
}

\begin{abstract}
This report details the evaluation of a community organization serving children and adolescents in Jamaica. The short-term goal of this study was to offer recommendations to the community organization. The long-term goal is to enhance services in order to improve child and adolescent outcomes in Jamaica. This study highlighted present trends for child and adolescent services in this community organization and provides an analysis that seeks to enhance those same services in the future. Recommendations include suggestions for increasing social programs, for increasing the impact of social programs on this inner-city community, and for exploring an approach to programming that benefits children and adolescents from this community.
\end{abstract}

Children and adolescents living in the inner city of Jamaica face the harsh realities associated with the poverty and physical decline of the community (United Nations Children's Fund [UNICEF] Jamaica, 2007). In 2003, Jamaica's total population was approximately 2.65 million, of which 977,000 , or $37 \%$, were children and adolescents under the age of 18 , half of whom lived in poverty (World Bank, 2003). Overall, despite declining growth rates, the level of all inner-city investment in social resources and services over the past three decades has not kept pace with the demands of supporting the basic needs of children and adolescents (World Bank, 2003). Consequently, children and adolescents in Jamaica have poor access to housing, education, employment opportunities, social services, and basic amenities (Aleph, 2002; Black, 2001; UNICEF Jamaica, 2006). This lack of essentials for children and adolescents weakens their opportunities to grow in secure foundations that generate emotional, social, and economic development (World Bank, 2004).

Living circumstances for children and adolescents in Jamaica have deteriorated to a deprive level (UNICEF Jamaica, 2006). Socioeconomic conditions in the community under study continue to contribute to high unemployment, intimidating levels of criminal activity, and disproportionate poverty (Black, 2001; United Nations, 2006). Conditions in this inner-city community are also complicated by political tribalism, subcultures, and turf wars, which in turn have led to the physical destruction of the area and stigmatization and victimization of residents by the wider community.

The following research question formed the framework for this study: How effective have child and adolescent services been in this community organization? 


\section{Deh Kidz in Jamaica: Evaluation of a Community Organization Serving Children and Adolescents}

\section{Methodology}

The community organization that is the subject of this report is located in a well-known, southern part of a large, inner-city community in Jamaica. This organization is a member of a larger association that exists for the promotion and well-being of children and adolescents. The organization takes a holistic approach by supporting physical, mental, social, and spiritual development. This study was an improvement-based, summative evaluation designed to focus on program enhancement and expansion (Fitzpatrick, Sanders, \& Worthen, 2004).

The research questions generated for this study were both qualitative and quantitative and employed a quasi-experimental approach, utilizing in part an interrupted time-series design. The design in part examined the causal relationship in which the outcomes of interest were observed over time. Specifically, the approach assessed the present trends for child and adolescent services in this community organization and provided analyses that is meant to lead to enhancement of those same services in the future.

In conjunction with the summative evaluation, an evaluation checklist generated from Stufflebeam's (2002) context, input, process, and product model was used as a process framework to support the research study. First, the impact evaluation checklist was placed into the present structure of the community organization to identify the concerns of this service organization. Then, input from the community and participants described the resources presently available and how those services impact the children and adolescents being served by this community organization. Lastly, the process of administering surveys and data collection to validate the community's concerns aided in making further recommendations to contribute to program improvements and future services. To guide this study, the researcher followed a services-development logic model. This model involved five steps:

1. First, the model helped in understanding the unmet service needs for children and adolescents and facilitated recommendations for current resources that are provided to children and adolescents in this community organization.

2. Second, the model allowed the planning of meetings with staff and community members at the community organization. These meetings assisted the researcher to understand the organizational resources and funding.

3. Third, the output of data achieved through surveys was based on the consideration of the staffing resources, number of volunteers, and community alliances at the time of surveying.

4. Fourth, the short-term outcome was simple: Make recommendations from the study for service needs forn finally, the long-term outcome would be to provide sustainable, enhanced services for children and adolescents in this community organization.

\section{Participants}

The population targeted in this study was 25 adolescents (16 to 18 years of age) who were involved in programming at the community organization; 25 parents, guardians, and advocates; and 25 administrators, teachers, and community members. The total number of participants was 75. All participants, regardless of age, were selected on the basis that they were 
of Jamaican descent, were living in the country, and had association with the community organization.

\section{Why This Community Organization?}

Programs for children and adolescents in this community organization have been active in Jamaica since 1923. Part of the community organization's mission is to meet the social, physical, emotional, and spiritual development of children and adolescents, in the community and on the island. This community organization is well respected in this inner city and the aim is to provide the following three services on limited resources for children and adolescents:

1. Improve the environment where children and adolescents live.

2. Provide programs that enhance the development of children and adolescents.

3. Promote participation in services that will develop the lives of children and adolescents.

Although theoretically children and adolescents are given priority in Jamaica's national documents and policies, allocation of resources has not been proportionate to the expressed objectives and has dwindled slowly over generations (Black, 2001; UNICEF Jamaica, 2006). This lack of resources is in part due to the systemic and complex nature of governmental practices (UNICEF, 2005).

\section{What is Jamaica's Priority?}

A 2005 budget analysis estimated the allotment for child and adolescent services was only $10.68 \%$ in 2004-2005 and slightly higher at 10.87\% in 2003-2004 (UNICEF Jamaica, 2006). This form of social exclusion should be reversed if children and adolescents are to survive, develop, participate, be protected in their communities, and be part of Jamaican society (UNICEF Jamaica, 2006).

Community leaders, organizations, and advocates have exhibited a strong drive to organize, mobilize, effectively lead, and participate in the renewal and redevelopment of services for children and adolescents. It is the desire of the community to hold the Jamaican government accountable for adhering to policies and plans that have been set forth in national documents (UNICEF Jamaica, 2007). This mobilization on the part of the non-profit sector appears to be the one positive force in this community (UNICEF Jamaica, 2004).

Community leaders, organizations, and advocates have been a part of the community for decades, while business and commerce have been moving out of the inner cities, further contributing to the decline in residential life (World Bank, 2004). The significant feedback from adolescents, parents and guardians, and community leaders recognized the existing child and adolescent services in this community organization and acknowledged the demand for basic programs (World Bank, 2004). Community leaders have explained that having access to costeffective, community-based initiatives will provide the basis for the standards, work ethics, patriotism, and discipline for which Jamaicans of past generations have been recognized (Thomas, 2005; World Bank, 2004). 


\section{What does the Literature Indicate?}

The review of relevant literature is divided into four sections. The first section focuses on the concept of services for children and adolescents. The aim of this section of the review was to stimulate an awareness of the issues regarding children and adolescents and to encourage an understanding of services related to them. The second section is a review of service areas and related interventions. The next section reviews literature regarding services and social environments. The last section summarizes services in Jamaica for children and adolescents and the practical implications for delivery of those services.

\section{Services}

A review of the relevant literature indicated that overall services for children and adolescents have become scarce, and investment choices must be made to maximize returns for better services (Karcher \& Lindwall, 2003). Services that provide health-related programming yield excellent results for children and adolescents (UNICEF Jamaica, 2005). Much of the literature (e.g., UNICEF, 2005) has explained that healthy children and adolescents reduce many of the pertinent risk factors (substance abuse, HIV/AIDS, etc.). Children and adolescents need access to health care to have healthy environments. The interconnectedness between health and related factors remains obvious for most children and adolescent services. The government in Jamaica has recognized this interconnectedness, though health programs and services overall seem to be poorly funded and weak (UNICEF Jamaica, 2005). However, UNICEF Jamaica (2007) reported that Jamaica has begun offering its youngest citizens free health care. Jamaica's prime minister has established a program in which Jamaicans aged 18 and under will be treated free of charge at the island's public hospitals and clinics (UNICEF Jamaica, 2007). The free program will cost between $\$ 5.2$ million and \$7.4 million annually (UNICEF Jamaica, 2007).

Yet, looking beyond health needs, there is a need for expansion of services that collaborate with the community sector, such as schools, governmental organizations, NGOs, and community organizations (United Nations, 2006). Encouraging collaboration in communities strengthens the understanding of the multiple issues, increases involvement, gives voice to the voiceless, and allows for multiple perspectives to be heard on a variety of issues (World Bank, 2003). With the capacity to collaborate about issues, a multisectoral response will develop coordination for better service delivery (Leadbeater et al., 2006). Increasing multisectoral responses will benefit and expand coverage to children and adolescents and their communities (Leadbeater et al.). This form of service delivery will enhance the power of programs and move towards a model of service that is seamless. Simply put, the world wants all children and adolescents to live full and healthy lives, with their rights secured and protected (UNICEF, 2007). In an ideal world with committed services and resources, all infants would start life healthy; all young children would be nurtured in caring environments; all children, including the poorest and most underprivileged, would complete a basic education of good quality; and all adolescents would have the prospect to develop fully and participate in their societies (UNICEF, 2007).

Conversely, White and Wyn (2004) supported the idea that needs far outweigh most countries' resources for services allotted to children and adolescents. Service initiatives for children and adolescents often become convoluted by political, social, and economic agendas 
and misplace the basic understanding of need. Despite these challenges, communities must move towards accountability and engagement if services are going to address the deficit (Wandersman et al., 2006). Engaging children and adolescents as partners whose input is important in the strengthening of services in communities and countries is vital. Often, children and adolescents have been placed in the background of their own villages (Voisin, 2007). Older children and adolescents often run their households, caring for their younger siblings or ailing family members, and many work long days in factories and in fields. Children and adolescents are, in effect, the villages in many countries and communities (UNICEF, 2007). Organizations should include children in the process of gaining experience through services and let them hone their skills and knowledge, so they can have meaningful influence on decisions that impact their lives (Schubert, 2007).

Jamaica relies on a collectivism that takes into consideration the needs, objectives, and values of the group, as opposed to those of the individual (UNICEF Jamaica, 2005). Partly because of a lack of resources, members of the community are interdependent, and children and adolescents participate in that collectivism, which sets forth the village approach to service delivery (UNICEF, 2005). Organizations such as UNICEF Jamaica (2004) recognize and value the collectivism by assembling services that include all groups in the population.

\section{Service Areas and Interventions}

Overall, the literature focused on four main service areas for children and adolescents: (a) promotion of healthy lives; (b) free quality education; (c) protection against abuse, exploitation, and violence; and (d) the battle against HIV/AIDS. The concerns for children and adolescents remain overwhelming for all countries, and the need for services is staggering (Best, 2007). Yet, progress has been made in the last couple of decades to provide children and adolescents with the necessities to become healthy members of society. In every region of the world, countries are moving forward with a diverse range of programs focusing on issues related to their population (Chen, Greenberger, Farruggia, Bush, \& Dong, 2003).

In Jamaica, service interventions for children and adolescents are a complex set of social policies; coverage of social services for children and adolescents spans everything from building schools and clinics to the more complex issues of how to improve the quality and efficiency of social services (United Nations, 2004). Jamaica's policymakers realize that without economic growth, a country will find it difficult to provide a sustainable basis to support social services (United Nations, 2004). Therefore, conditions that threaten economic stability are likely to have a negative impact on a country's ability to fund social services. With this in mind and using Jamaica as an example, the greatest challenges in most countries involve the sustainability of social services, because of economic stability (UNICEF, 2005). Social services initiatives in most countries are a priority in theory, but not in practice. However, guaranteeing services for children and adolescents in any country requires a legal and moral responsibility. To advocate for social investment in children and adolescents means accountability that visualizes future social and economic development and a prosperous country (UNICEF, 2005).

Services for children and adolescents span the globe. To improve the lives of children and adolescents, it is necessary to determine their circumstances, their needs, and the services they require to meet those needs (Seginer \& Lilach, 2004). It is simple: People who develop and provide services to assist children and adolescents should gather accurate and culturally specific 
information that provides appropriate support and committed services (Leadbeater et al., 2006). The world should be made aware that the welfare of more than 140 million children and adolescents is at stake (World Bank, 2003).

\section{Programs and Social Environments}

The foundation for any child and adolescent service should be programs that make progress in environments where children and adolescents are the most vulnerable (Nayak, 2003). Programs have the ability to move forward, make change, and eliminate the need for services. Organizations can draw together and create opportunities for the eradication of many of the issues children and adolescents experience (Thompson, 2006). The purpose of any program should be developed around the philosophy of leadership, human rights, health, security, dignity, freedom, justice, and peace (Peer Assistance and Leadership, 2004). Yet, social environments are not always structured for such a commitment.

Traditionally, child and adolescent programs in North America have filtered through institutions in the social service system, which customarily have borne the responsibility for taking care of concerns regarding children and adolescents (DuBois \& Karcher, 2005). Social service programming in North America has been associated with social serving agencies; further, depending on the environment, communities have the support of private funds, which develop and take responsibility for children and adolescent programs and services (DuBois \& Karcher). The environmental structure in North America is quite different than that in other countries, as North America appears to have plenty of resources to serve the needs of children and adolescents (Scales, 2003). Yet, the common thread of never having enough services appears to be the connection between North America and the rest of the world (United Nations, 2006).

Children and adolescents in the Caribbean have negative outcomes as a result of failures on the part of policies and programs that do not address and support their needs (World Bank, 2003). The target of Jamaica and the Caribbean as a whole is the social development and social welfare of children and adolescents, having set up many departments and resources. However, limited empirical data and accountability have accompanied the social development and resources that have been established (UNICEF Jamaica, 2006). Many programs and services in Jamaica focus on leisure activities and overlook an understanding of the needs and challenges of children and adolescents (UNICEF Jamaica, 2006).

Jamaica, like many other developing countries, has been impacted positively and negatively by globalization (United Nations, 2004). The rapid development of telecommunications and computer technology has increased the quantity and speed of information shared between children and adolescents in Jamaica and across the globe (United Nations, 2004). The Internet has made children and adolescents in Jamaica acutely aware of others, and they have gained information that otherwise would not be accessible to them (UNICEF, 2007). Hence, a growing number of very knowledgeable young people understand the issues and their social environments and are asking questions. Questions mean accountability; slowly, Jamaican children and adolescents are realizing how social development influences their views on justice and equality, and they are curious about the actions of governments and outside organizations (UNICEF Jamaica, 2007). Technology has empowered Jamaica's young people to start asking questions, which is a step forward for this generation and will give rise to responsibility for issues pertaining to children and adolescents (United Nations, 2004). 


\section{Deh Kidz in Jamaica: Evaluation of a Community Organization Serving Children and Adolescents}

This literature review identified issues pertaining to the programming and social environments of children and adolescents. These three issues transcend all parts of the world and reflect aspects of global uniformity (International Labour Organization, 2004):

1. Some children and adolescents are trapped in poverty and some are not.

2. Some benefit from new social and human service resources and technologies and some lack access to them (United Nations, 2004).

3. Some children and adolescents pursue their ideas in an unwavering environment of structure and security, and some are unfortunate enough to become trapped in constant conflict, both in their homes and countries (United Nations, 2004).

These disparities and inequalities between children and adolescents of the world need to be eradicated (UNICEF, 2007). Most importantly, making the world's policies, programs, and social environments accountable for children and adolescents would be a step towards true progress.

\section{Overview of Jamaica and Services for Children and Adolescents}

Overall, Jamaica's children and adolescents are still governed by a collectivism that has been entrenched culturally and rooted in Jamaican history (Aleph, 2002; Thomas, 2005). The island population has had to rely on resources that mostly include immediate and extended family to ensure the welfare of the younger generation (UNICEF Jamaica, 2006). Thus, it would be negligent for practitioners not to consider and understand the collectivist ideology when evaluating the services provided to children and adolescents in Jamaica (UNICEF, 2005). Like many countries outside the Westernized philosophy, communities guide generations through wisdom, experience, and history. Community collectivism in Jamaica and the Caribbean has attempted to establish an identity for children and adolescents and to counteract some of the media influence (United Nations, 2004).

The Caribbean is no different than other regions in terms of what program developers want to see for children and adolescents in areas of their achievement. There are minimal differences in the way that non-profit agencies plan effective practices and program development in North America, the Caribbean, and other regions of the world (UNICEF Jamaica, 2006). Children and adolescents need protective environments so they become active participants as adults, and if that environment is not provided in any facet of their lives, they tend to flounder (United Nations, 2004).

Jamaica has a wide range of developmental concerns requiring social service interventions for children and adolescents. As a result, service needs on the island are many and varied. Traditionally, programs and services on the island include tutoring from preschool through community college, helping children and young adults with basic literacy and coping skills, health care clinics, health education, drug abuse programs that address medical issues, microbusiness, and women's projects that contribute to community and economic development (UNICEF, 2007).

Typically, the government is primarily responsible for services and programs administered to children and adolescents. The various ministries have a targeted amount that is 
given to services, which has not been managed efficiently (National Center for Youth Development, 2003). In order to better direct and lessen waste of resources because of overlap and duplication in services, coordination among government bodies is needed (National Center for Youth Development). Individual organizations often seek private institutions for further funding. The Ministry of Education, Youth, and Culture tries to provide consistent funding, and programs such as the National Youth Service operate under the auspices of the ministry. Yet, priorities and mandates are not always service initiatives for this population (National Center for Youth Development).

The Jamaican government has published the final draft of the National Youth Policy pointing out that educational and life skills development will elevate young people to move towards their full potential (National Center for Youth Development, 2003). This policy documents goals that young Jamaicans will progress and contribute to their community and country through the acquisition of knowledge, skills, and competencies (UNICEF Jamaica, 2006). The policy is part of the government's larger national vision for the country from 2003 to 2015. It is one of the few pieces of literature that states what is desired and includes many community agencies as contributors (National Center for Youth Development). Pessimism remains when governments create policies but do not have the resources to back up recommendations. As a result, redundant documents explain the problems of children and adolescents, with few resources allocated for interventions (UNICEF, 2006).

Child and adolescent programming staff in Jamaica strive to work with the limited resources to create different levels of outcomes and interventions, which accommodate multiple levels in programming (World Bank, 2003). The various levels of services provided to children and adolescents are similar to an umbrella, with a spectrum and varying degrees of complexities (Canino \& Spurlock, 2004). Commonly cited themes and issues are living environments, education and training, employment and entrepreneurship, health, participation and empowerment, and care and protection (World Bank, 2003, 2004).

Countries such as Jamaica often lack the manpower or resources to become sophisticated in child and adolescent service delivery (National Center for Youth Development, 2003; Thomas, 2005). Although social service practitioners in Jamaica want successful outcomes, it is difficult to use some of the principles set forth in North American literature. Whereas North American mainstream service outcomes can be used for the basic application of service delivery, the emerging information and literature from NGOs in developing countries should be examined because of their direct contact with countries, community organizations, and service providers (Wandersman et al., 2006). Programs and interventions should be modified to meet the ethnically specific service needs and identify how they differ for children and adolescents in different countries (UNICEF, 2005).

Over the years, Jamaica and different NGOs have developed a comprehensive understanding of responses needed to tackle the root causes of child and adolescent exclusion (UNICEF Jamaica, 2005). Services need to be consolidated, expanded, and reviewed to take into account new dimensions of social service integration (UNICEF Jamaica, 2005). Further, encouraging research and interventions from both island and foreign resources will promote better programming and planning for the benefit of children and adolescents in the future (United Nations, 2004). 
Ultimately, long-term outcomes need to be the mission of service delivery for children and adolescents in Jamaica. First, to achieve long-term outcomes and goals, officials initially must identify the issues affecting children and adolescents and understand they are not limited to one sector; thus, the response cannot be devised successfully by any one ministry or agency (National Center for Youth Development, 2003). Additionally, the identifiable information regarding the issues affecting this population should be distributed to the government, private sector, NGOs, and community-based initiatives (National Center for Youth Development). Next, a network of awareness should be established both in the traditional sense and through electronic networks. Lastly, children and adolescents should be involved in the exchange to ensure that themes, outcomes, and information are accurate in relation to what is going on in their communities (UNICEF, 2005). Jamaica has the basic framework that is needed to achieve generational change and movement in child and adolescent services (National Center for Youth Development). Clearly, work needs to be done by many sectors in Jamaica to accomplish longterm goals and objectives that are measurable.

\section{Summary of the Literature}

This literature review illustrated that child and adolescent services have great potential on many levels. By virtue of their membership in a community, neighbourhood, school district, and cultural group, children and adolescents are shaped by the world around them $(\mathrm{K}$. McCluskey, Noller, Lamoureux, \& A. McCluskey, 2004). Programs that are well developed usually have sustainable research that affords them further funding for continued progress (Nayak, 2003). Yet, to impose lessons from progressive nations on less affluent countries with inadequate resources can be counterproductive (National Center for Youth Development, 2003). The reality of resource constraints for countries implies selectivity of child and adolescent services for those environments. Yet, a clear message is developing in the literature: Children and adolescents are not the problem, but a derivative of their environments (Weissberg, Walberg, Utne-O'Brien, \& Bartels-Kuster, 2003).

As a whole, it is difficult to know the impact and effectiveness of child and adolescent services. Even though countries are acknowledging and implementing programs on different levels, when neither systems nor proper data analysis are monitored, the quantity of effectiveness is called into question (UNICEF, 2007). The multitude of programs in place to address issues related to children and adolescents is endless. Yet, worldwide little exists in the way of evaluative practices for initiatives related to children and adolescents (Jones \& Perkins, 2006).

Despite progress on many accounts, children and adolescents worldwide still suffer the worst from economic and social disparities; problems are felt most deeply by children and adolescents living in extremely poor urban and rural communities (United Nations, 2006). Organizations all over the world need to continue to improve living circumstances of children and adolescents by fostering self-sustaining programs such as literacy, skills training, community development, and proper health care (UNICEF, 2007). The recognition that services are an investment in the building of human and social capital is the best hope for children and adolescents and a necessity for economic growth and social peace (UNICEF, 2007). 


\section{Conclusion}

This study was designed to evaluate a community organization that serves children and adolescents in Jamaica. The community organization involved in this study was open to examining the issues related to child and adolescent services because of the overall lack of resources: poor access to housing, education, employment opportunities, social services, and basic amenities (Aleph, 2002; Black, 2001; UNICEF Jamaica, 2006). Deficiency in resources leads to a greater lack of essentials for children and adolescents in Jamaica and weakens their opportunities to grow in secure foundations that generate emotional, social, and economic development (World Bank, 2004). As a result of substantiating the program deficits through this study, concerns and interests were identified, and efforts can now begin to form alternatives for serving children and adolescents in this inner-city community and in Jamaica as a whole. The issues experienced by the children and adolescents who participated in this study served are not the fault of these young people, but are essentially the by-product of their micro and macro environments, which have produced reduced opportunities for them (World Bank, 2003). In an effort to change those consequences with a view to increasing child and adolescent opportunities, the following services need to be emphasized: investing in social programming in a collaborative manner, understanding the correlation between social programming and resource deficits, identifying key trends suggested by the literature, ensuring community participation, and recognizing the culture and tradition of children and adolescents in Jamaica. 


\section{References}

Aleph, S. A. (2002). Youth in Jamaica: Meeting their development needs. Kingston, Jamaica: Ministry of Education, Youth, and Culture, National Center for Youth Development.

Best, A. L. (2007). Representing youth: Methodological issues in critical youth studies. New York: New York University Press.

Black, S. (Director \& Producer). (2001). Life and debt [Motion picture]. United States: Tuff Gong Pictures.

Canino, I. A., \& Spurlock, J. (2004). Culturally diverse children and adolescents: Assessment, diagnosis, and treatment (2nd ed.). New York: Guilford Press.

Chen, C., Greenberger, E., Farruggia, S., Bush, K., \& Dong, Q. (2003). Beyond parents and peers: The role of important non-parental adults (VIPS) in adolescent development in China and the United States. Psychology in the Schools, 40, 35-50.

DuBois, D., \& Karcher, M. (2005). Handbook of youth mentoring. Thousand Oaks, CA: Sage.

Fitzpatrick, J. L., Sanders, J. R., \& Worthen, B. R. (2004). Program evaluations: Alternative approaches and practical guidelines (3rd ed.). New York: Pearson Education.

International Labour Organization. (2004). Global employment trends for youth. Geneva, Switzerland: Author.

Jones, K. R., \& Perkins, D. F. (2006). Youth and adult perceptions of their relationships within community-based youth programs. Youth \& Society, 38, 90-109.

Karcher, M. J., \& Lindwall, J. (2003). Social interest, connectedness, and challenging experiences. What makes high school mentors persist? Journal of Individual Psychology, 59(3), 293-315.

Leadbeater, B., Banister, E., Benoit, C., Jansson, M., Marshall, A., \& Riecken, T. (2006). Ethical issues in community-based research with children and youth. Toronto: University of Toronto Press.

McCluskey, K., Noller, R., Lamoureux, K., \& McCluskey, A. (2004). Unlocking hidden potential through mentoring. Journal of Strength-Based Interventions, 13(2), 85-93.

National Center for Youth Development. (2003). National Youth Policy. Kingston, Jamaica: Ministry of Education, Youth, and Culture.

Nayak, A. (2003). Race, place and globalization: Youth cultures in a changing world. Oxford, UK: Berg.

Peer Assistance and Leadership. (2004). PAL peer assistance and leadership. Retrieved July 18, 2006, from http://www.peerprograms.org 
Scales, P. C. (2003). Other people's kids: Social expectation and American adults' involvement with children and adolescents. New York: Kluwer Academic Press.

Schubert, J. (2007). Engaging youth with the power of listening. Reclaiming Children and Youth, 15(4), 227-228.

Seginer, R., \& Lilach, E. (2004). How adolescents construct their future: The effect of loneliness on future orientation. Journal of Adolescence, 27(6), 625-643.

Stufflebeam, D. L. (2002). Evaluation models. San Francisco: Jossey-Bass.

Thomas, D. (2005). Modern Blackness: Nationalism, globalization and the politics of culture in Jamaica. Durham, NC: Duke University Press.

Thompson, R. A. (2006). Nurturing future generations: Promoting resilience in children and adolescents through social, emotional, and cognitive skills. New York: Routledge.

United Nations. (2004). World youth report, 2003: The global situation of young people. New York: United Nations Development Programme.

United Nations. (2006). World youth report, 2005: Young people today and in 2015. New York: United Nations Development Programme.

United Nations Children's Fund. (2005). Investing in child and adolescents: Arguments and approaches for advocacy. Retrieved June 1, 2007, from http://www.unicef .org/publications

United Nations Children's Fund. (2007). The state of the world's children, 2007. Retrieved March 16, 2007, from http://www.unicef.org/publications

United Nations Children's Fund Jamaica. (2004). Advancing children's rights in Jamaica. Report on legislative reform initiative. Retrieved September 16, 2006, from http://www.unicef.org/jamaica

United Nations Children's Fund Jamaica. (2005). Situation analysis of Jamaican children. Retrieved September 16, 2006, from http://www.unicef.org/jamaica

United Nations Children's Fund Jamaica. (2006). Situation analysis on excluded children in Jamaica. Retrieved September 16, 2006, from http://www.unicef.org/jamaica

United Nations Children's Fund Jamaica. (2007). The 2007-2011 government of Jamaica/UNICEF country program. Retrieved March 16, 2007, from http://www .unicef.org/Jamaica

Voisin, D. R. (2007). The effects of family and community violence exposure among youth: Recommendations for practice and policy. Journal of Social Work Education, 43(1), 51-66. 
Wandersman, A., Clary, E. G., Forbush, J., Weinberger, S. G., Coyne, S. M., \& Duffy, J. L. (2006). Community organizing and advocacy: Increasing the quality and quantity of mentoring programs in the community. Journal of Community Psychology, 34(6), 781-799.

Weissberg, R. P., Walberg, H. J., Utne-O’Brien, M., \& Bartels-Kuster, C. (2003). Long-term trends in the well-being of children and youth. Washington, DC: CWLA Press.

White, R., \& Wyn, J. (2004). Youth and society: Exploring the social dynamics of youth experience. South Melbourne, Australia: Oxford University Press.

World Bank. (2003). Caribbean youth development: Issues and policy direction. Washington, DC: Author.

World Bank. (2004). The road to sustained growth in Jamaica. Washington, DC: Author.

Leslie Yaffa PhD, has spent 20 years in the field of human and social services and has held clinical social work positions in hospital, community and agency settings. Currently, she works in private practice and is a full-time faculty member at the University of New England in Maine in the online MSW program. She teaches in the MSW program at the University of Toronto and in the CYC program at Ryerson University. Leslie is the founder of the Walk Good Foundation, which uses research to support program development and cost-effective services to children and adolescents in Jamaica and the Caribbean. 